
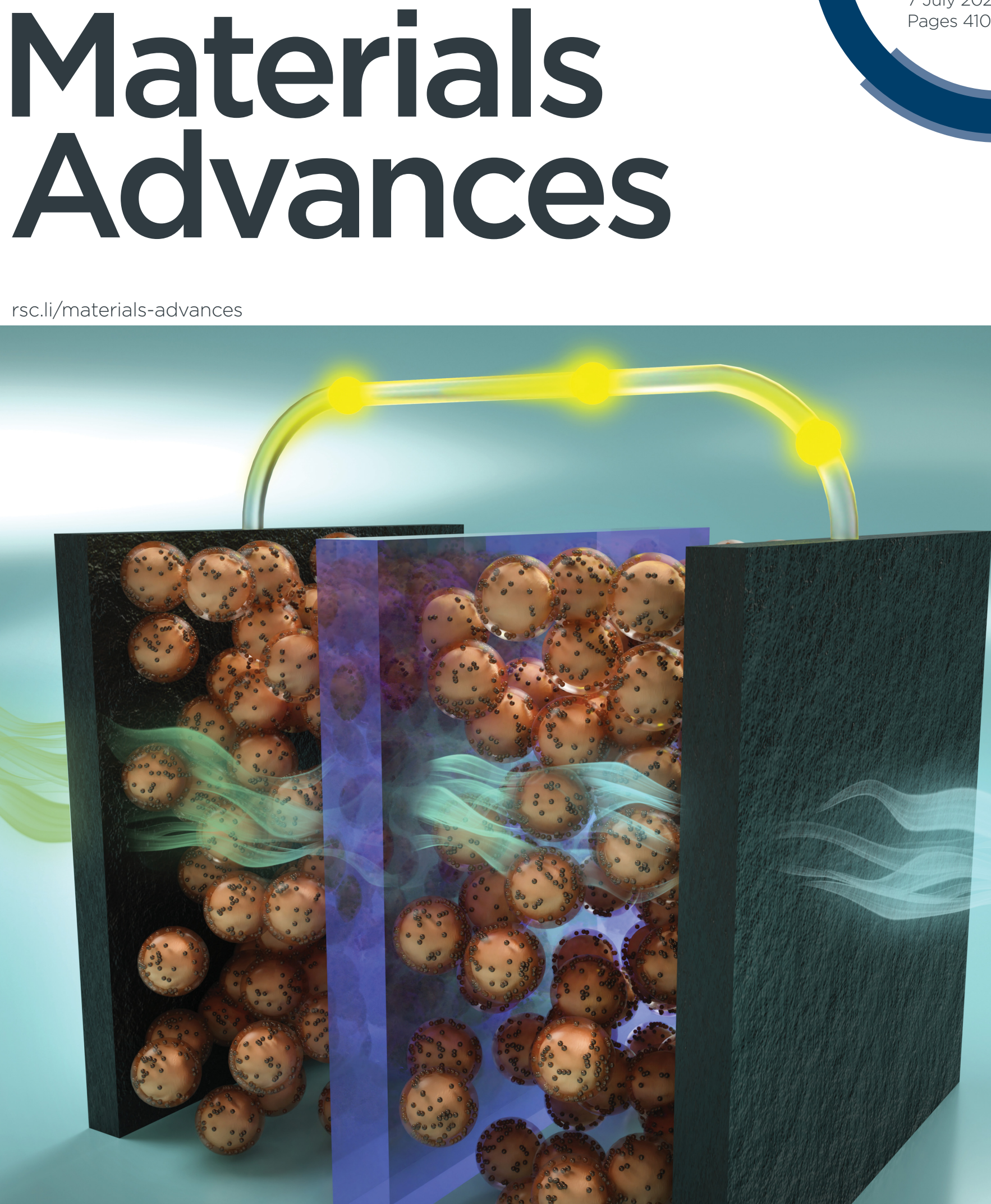
Check for updates

Cite this: Mater. Adv., 2021, 2, 4228

Received 9th March 2021, Accepted 12th May 2021

DOI: $10.1039 / \mathrm{d} 1 \mathrm{ma} 00208 \mathrm{~b}$

rsc.li/materials-advances

\section{Correlating high temperature thin film ionomer electrode binder properties to hydrogen pump polarization $\dagger$}

\author{
Gokul Venugopalan, (D) a Deepra Bhattacharya, (D) a Subarna Kole, (D) \\ Cameron Ysidron, ${ }^{\mathrm{a}}$ Polyxeni P. Angelopoulou, ${ }^{\mathrm{b}}$ Georgios Sakellariou (D) ${ }^{\mathrm{b}}$ and \\ Christopher G. Arges (D) *a
}

lonomer electrode binders are important materials for polymer electrolyte membrane (PEM) fuel cells and electrolyzers and have a profound impact on cell performance. Herein, we report the effect of two different types of high-temperature (HT) ionomers, characterized as thin films ( $10 \mathrm{~nm}$ ), on hydrogen oxidation/evolution reaction (HOR/ HER) kinetics and hydrogen permeability using interdigitated electrode (IDE) platforms decorated with nanoscale platinum electrocatalysts. The two different ionomers studied were poly(tetraflurostyrene phosphonic acid-co-pentafluorostyrene) (PTFSPA) and quaternary benzyl pyridinium poly(arylene ether sulfone) imbibed with phosphoric acid $\left(\mathrm{QPPSf}-\mathrm{H}_{3} \mathrm{PO}_{4}\right.$ ). The reaction kinetics and limiting current values observed with thin film ionomers on IDEs were commensurate to the values observed in electrochemical hydrogen pumps (ECHPs) that use the ionomers as electrode binders. Using PTFSPA as the binder, an HT-PEM ECHP showed $1 \mathrm{~A} \mathrm{~cm}^{-2}$ at $55 \mathrm{mV}$ when using $2 \mathrm{mg}_{\mathrm{Pt}} \mathrm{cm}^{-2}$ in the membrane electrode assembly.

\section{Introduction}

Ionomer binders strongly influence the performance and stability of numerous electrochemical processes such as fuel cells, ${ }^{1-4}$ water $^{5}$ and carbon dioxide electrolyzers, ${ }^{6}$ and deionization units. $^{7,8}$ In low- and high-temperature polymer electrolyte membrane (i.e., LT-PEM and HT-PEM) architectures involving hydrogen, the binders hold the electrocatalyst/electrocatalyst supports, while also delivering protons to and from the electrocatalyst to the PEM separator. Both PEM separators and ionomer electrode binders require high conductivity and stability ${ }^{4,9}$ under a wide-range of conditions (e.g., chemical, electrochemical, and

\footnotetext{
${ }^{a}$ Cain Department of Chemical Engineering, Louisiana State University, Baton Rouge, LA, 70803, USA. E-mail: carges@lsu.edu

${ }^{b}$ Department of Chemistry, National and Kapodistrian University of Athens, Athens 15771, Greece

$\dagger$ Electronic supplementary information (ESI) available. See DOI: 10.1039/ d1ma00208b
}

thermal), but there are nuanced differences with respect to the properties for PEM separators and electrode binders. PEM separators necessitate low gas permeability for safety and mitigating mixed overpotentials. Ionomer binders require high gas permeability to overcome mass transfer related resistances and enable high current density. ${ }^{10,11}$

In the electrode layers, the ionomer binder often serves as a thin adhesive coating on the electrocatalyst/electrocatalyst support particles. ${ }^{12}$ A few research groups have shown that Nafion ${ }^{\circledR}$ can display substantially different proton conductivity and water uptake properties when confined as a thin film (5 to $100 \mathrm{~nm}$ ) when compared to its properties as a bulk membrane. ${ }^{13-19}$ It is worth noting that there is a lack of studies investigating how the properties of other thin film ionomers influence electrochemical properties, such as charge-transfer reaction kinetics as well as gas permeability, in addition to other types of ionomer chemistries for hydrogen-based electrochemical systems. These other properties have a more profound impact on electrochemical device performance when compared to ionic conductivity. ${ }^{20}$ For example, ionomers can alter redox reaction rates (e.g., by adsorption of the tethered ion to the catalyst $)^{21,22}$ and gas reactant mass transfer rates to the electrocatalyst surface. ${ }^{11,20,23,24}$

In this work, we studied the influence of two different types of high-temperature ionomer thin films on hydrogen oxidation/ evolution reaction (HOR/HER) kinetics and hydrogen gas permeability on interdigitated electrodes (IDEs). We then correlated the thin film properties to the polarization behavior of electrochemical hydrogen pumps (ECHPs). Our work was motivated by our previous reports, ${ }^{20,25,26}$ and others, ${ }^{3,27-29}$ showing that ion-pair HT-PEMs operate over a wider temperature range and have greater humidity tolerance when compared to the conventional benchmark based upon phosphoric acid $\left(\mathrm{H}_{3} \mathrm{PO}_{4}\right)$ imbibed polybenzimidazole. In HT-PEM fuel cell studies, we observed significant kinetic and mass transfer resistances that hail from the presence of liquid $\mathrm{H}_{3} \mathrm{PO}_{4}$ in the electrode layers. To address these resistances, Los Alamos and the University of 
Stuttgart adopted an alternative ionomer electrode binder based upon tethered phosphonic acid to the polymer backbone (i.e., poly(tetrafluorostyrene phosphonic acid-co-pentafluorostyrene) (PTFSPA)). ${ }^{1}$ This binder addressed mass transfer resistances in the electrode layers and achieved a peak power density of $1.7 \mathrm{~W} \mathrm{~cm} \mathrm{~cm}^{-2}$ at $240{ }^{\circ} \mathrm{C}$. Drawing inspiration from this group, we investigated how removal of liquid acid from the ionomer influences HOR/HER kinetics and gas permeability. We then related the properties of thin films to the polarization of a single-cell electrochemical hydrogen pump (ECHP).

ECHPs are used for hydrogen separations and compression in industrial settings, ${ }^{30-36}$ in addition to being a diagnostic tool for fuel cells. Combining the ion-pair HT-PEM separator with $\mathrm{Pt} / \mathrm{C}$ electrodes using the PTFSPA binder, we have demonstrated that an ECHP that can operate at $1 \mathrm{~A} \mathrm{~cm}^{-2}$ at $120 \mathrm{mV}$ using $1 \mathrm{mg}_{\mathrm{Pt}} \mathrm{cm}^{-2}$ in the membrane electrode assembly (MEA) and at $55 \mathrm{mV}$ at $220{ }^{\circ} \mathrm{C}$ using $2 \mathrm{mg}_{\mathrm{Pt}} \mathrm{cm}^{-2}$ in the MEA. These values represent the best performance in the peer-reviewed literature for a HT-PEM ECHP. However, it should be noted that LT-PEMs (e.g., perfluorosulfonic acid materials like Nafion $\left.{ }^{\circledR}\right)$, using humidification, can achieve the same current density values at lower voltage $(0.04 \text { to } 0.09 \mathrm{~V})^{34,35}$ at lower platinum loadings $\left(<1 \mathrm{mg}_{\mathrm{Pt}} \mathrm{cm}^{-2}\right.$ for the MEA). Although LT-PEM ECHPs have better performance, they require substantial gas humidification and suffer more in performance loss with greater concentration of contaminants in the hydrogen mixture (e.g., carbon monoxide (CO)). Raising the temperature above $180{ }^{\circ} \mathrm{C}$ makes the ECHP more resilient to contaminants enabling more effective hydrogen separations. Also, the environment for HT-PEM ECHP is not as harsh as HT-PEMFC and LT-PEM ECHP as the cell has no oxygen and water.

Most ECHP studies that operate above $100{ }^{\circ} \mathrm{C}$ examine different types of PBI chemistries..$^{30-33,37,38}$ These studies often use commercially available electrodes (e.g., BASF electrodes) and little attention has been given to how the electrode binder impacts ECHP performance. New materials for fuel cells, ECHPs, and water electrolyzers are characterized in ex situ experimental setups for assessing their likelihood to improve the electrochemical cell performance. Experimental protocols for ex situ assessment of bulk membranes (e.g., 4 pt conductivity) and electrocatalyst activity (e.g., rotating disk electrode) are standardized, but there are few precedents and tools to examine the electrochemical properties of thin film ionomers ${ }^{11,39}$ outside ionic conductivity and without liquid supporting electrolyte.

\section{Results and discussions}

To understand how thin film ionomers impact other electrochemical properties beyond ionic conductivity, our group developed an interdigitated electrode (IDE) platform that features a thin film $(<30 \mathrm{~nm})$ of nanoscale platinum group metal (PGM) electrocatalyst afforded from self-assembled block copolymer templates ${ }^{40}$ (Fig. 2a). The electron micrograph of platinum nanowires on IDEs is shown in Fig. $\mathrm{S} 1$ (ESI $\dagger$ ), while images of the chamber for HOR/ HER experiments are provided in Fig. S2 (ESI $\dagger$ ). The presence of this periodic nanostructure PGM electrocatalyst across the IDE is useful for assessing HOR/HER kinetics in the presence of a thin film ionomer (previously Nafion ${ }^{\circledR}$ at room temperature). ${ }^{40}$ Here, we extended this platform to assess the electrochemical properties (HOR/HER kinetics, ionic conductivity, and hydrogen permeability) for two different types of thin film high-temperature (HT-) ionomers. The chemical structures of the HT-ionomers (PTFSPA and quaternary benzyl pyridinium poly(arylene ether sulfone) imbibed with $\mathrm{H}_{3} \mathrm{PO}_{4}$ (QPPSf $\left.\mathrm{H}_{3} \mathrm{PO}_{4}\right)$ ) are shown in Fig. 1a. PTFSPA was synthesized following the procedure of Atanasov et al. ${ }^{41}$ QPPSf $\mathrm{H}_{3} \mathrm{PO}_{4}$ was prepared as described in our previous work. ${ }^{26}$ The scheme for the chemical synthesis of PTFSPA and the NMR spectra for PTFSPA and QPPSf $\mathrm{H}_{3} \mathrm{PO}_{4}$ are provided in Fig. S3-S5 in the ESI. $\dagger$ The IEC values for these materials are provided in the ESI. $\dagger$ The TGA data of the different ionomers are given in Fig. S6 (ESI $\dagger$ ).

Prior to running polarization experiments in the presence of hydrogen, the ionic conductivity $(\kappa)$ of the ionomers (QPPSf $\mathrm{H}_{3} \mathrm{PO}_{4}$, PTFSPA before exposure to $\mathrm{H}_{3} \mathrm{PO}_{4}$, and PTFSA after a.)

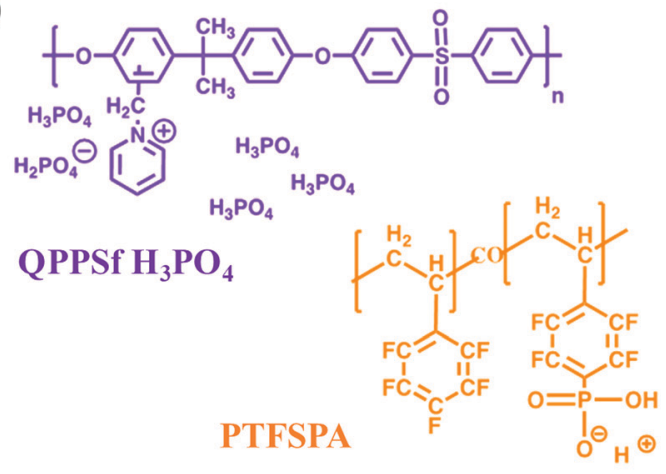

b.)

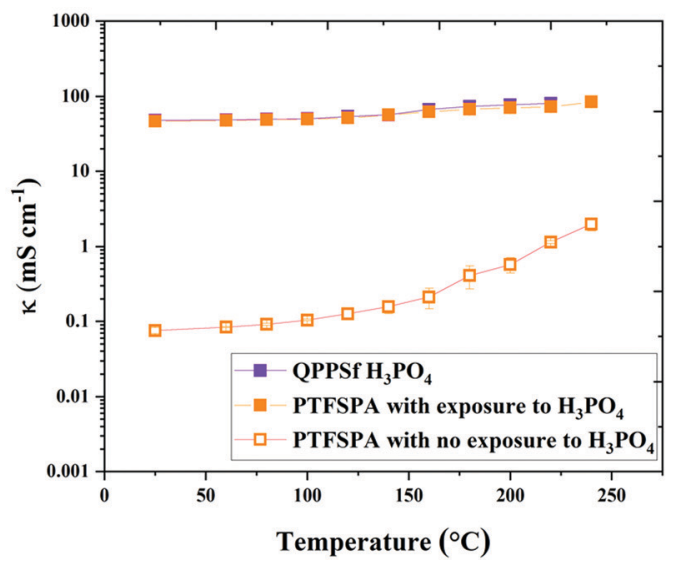

Fig. 1 (a) The chemical structures of the HT-ionomer thin films and electrode binders characterized and used in this work. (b) Thin film ionic conductivity as a function of temperature for QPPSf $\mathrm{H}_{3} \mathrm{PO}_{4}$ PTFSPA before exposure to $\mathrm{H}_{3} \mathrm{PO}_{4}$ and after exposure to $\mathrm{H}_{3} \mathrm{PO}_{4}$. 
exposure to $\mathrm{H}_{3} \mathrm{PO}_{4}$ ) as thin films was determined as a function of temperature in the presence of dry nitrogen on IDEs (Fig. 1b). PTFSPA thin films after activation with 5 wt $\%$ $\mathrm{H}_{3} \mathrm{PO}_{4}$ for 10 minutes, has the same ionic conductivity as QPPSf $\mathrm{H}_{3} \mathrm{PO}_{4}$ up to $125{ }^{\circ} \mathrm{C}$, and its conductivity value is within 5 to $10 \mathrm{mS} \mathrm{cm}{ }^{-1}$ of QPPSf $\mathrm{H}_{3} \mathrm{PO}_{4}$ in the temperature range of 150 to $225{ }^{\circ} \mathrm{C}$. The ionic conductivity of PTFSPA thin film without exposure to $\mathrm{H}_{3} \mathrm{PO}_{4}$ for activation is very low compared to QPPSf $\mathrm{H}_{3} \mathrm{PO}_{4}$ and PTFSPA exposed to $\mathrm{H}_{3} \mathrm{PO}_{4}$. The ionic conductivity of the PTFSPA thin film without exposure to $\mathrm{H}_{3} \mathrm{PO}_{4}$ rapidly increased from $10^{-2}$ to $2 \mathrm{mS} \mathrm{cm} \mathrm{cm}^{-1}$ as the temperature increased from $100{ }^{\circ} \mathrm{C}$ to $220{ }^{\circ} \mathrm{C}$.

The ability of PTFSPA to provide adequate ionic conductivity without the need for water and an imbibed acid across a wide temperature range makes it a good candidate for HT-PEM fuel cells and ECHPs. It was anticipated that the removal of liquid $\mathrm{H}_{3} \mathrm{PO}_{4}$ would enhance mass transfer in the electrodes in the devices as well as improve redox kinetics. $\mathrm{H}_{3} \mathrm{PO}_{4}$ has a detrimental effect on oxygen reduction reaction (ORR) kinetics in HT-PEM fuel cell cathodes because of phosphate anion adsorption on the platinum catalyst surface. ${ }^{42}$

After the ionic conductivity experiments were completed, the nitrogen gas was switched to dry hydrogen (i.e., $0 \% \mathrm{RH}$ ), and chronoamperometry experiments were performed from $0 \mathrm{~V}$ to $0.7 \mathrm{~V}$ at temperatures of $160{ }^{\circ} \mathrm{C}, 180{ }^{\circ} \mathrm{C}$, and $200{ }^{\circ} \mathrm{C}$ on the IDEs shown in Fig. 2a. Temperatures above $200{ }^{\circ} \mathrm{C}$ were not investigated due to the instability of the IDE platform for extended periods of time at that temperature. The iR-corrected polarization curves are plotted with IDEs in Fig. $2 \mathrm{~b}$, featuring the two different high-temperature ionomers as a function of temperature (the polarization curves without iR-correction are given in Fig. S7, ESI $\dagger$ ). In this plot, the PTFSPA thin film displayed larger current responses in the linear regime, as well as larger limiting currents, over the QPPPSf- $\mathrm{H}_{3} \mathrm{PO}_{4}$ thin film. Notably, the PTFSPA showed larger increases in current density across the voltage range as a function of temperature when referenced against QPPPSf- $\mathrm{H}_{3} \mathrm{PO}_{4}$.

To quantify the improvements in HOR/HER with thin film PTFSPA over QPPPSf- $\mathrm{H}_{3} \mathrm{PO}_{4}$, we first analyzed the limiting current density values of the iR-corrected polarization curves. The limiting current corresponds to limitations from mass transfer resistances that arrive from gaseous permeability across the thin film ionomer. Gas permeability $\left(P_{\mathrm{H}_{2}}\right)$ is a product of the species diffusion coefficient $\left(D_{\mathrm{H}_{2}}\right)$ multiplied by its solubility coefficient (e.g., Henry's constant $-H_{\mathrm{H}_{2}}$ in this case) in the polymer electrolyte thin film (eqn (1)). By knowing

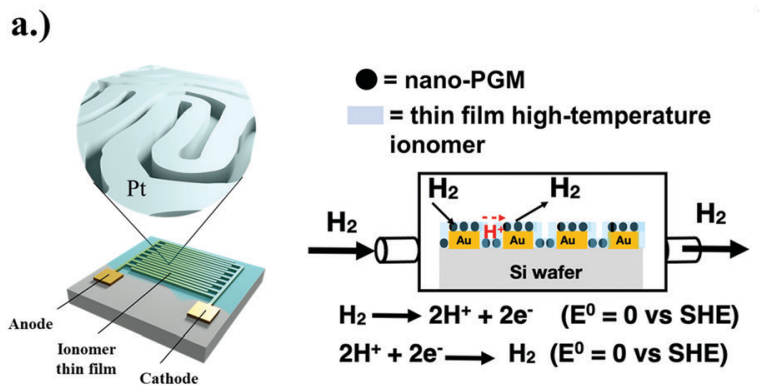

b.)

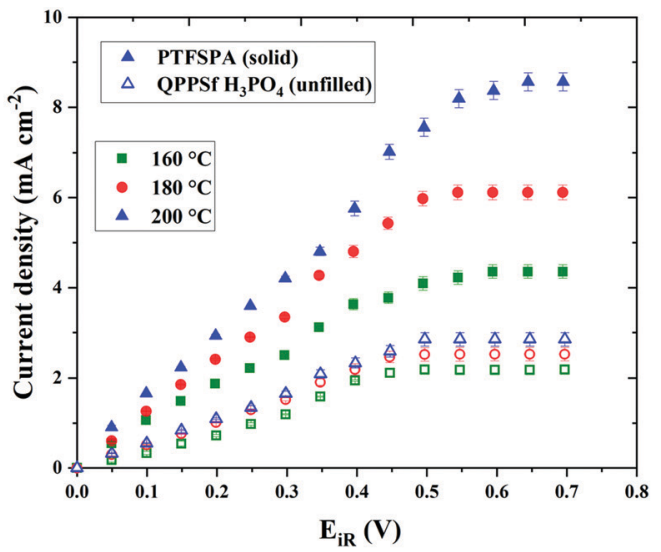

c.)

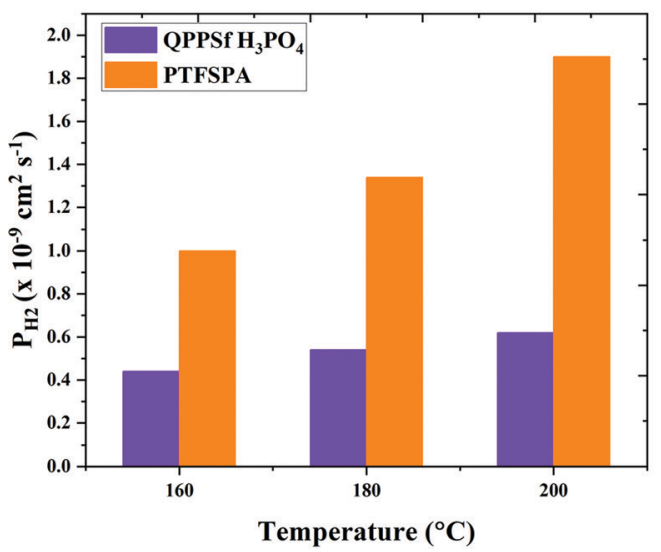

d.)

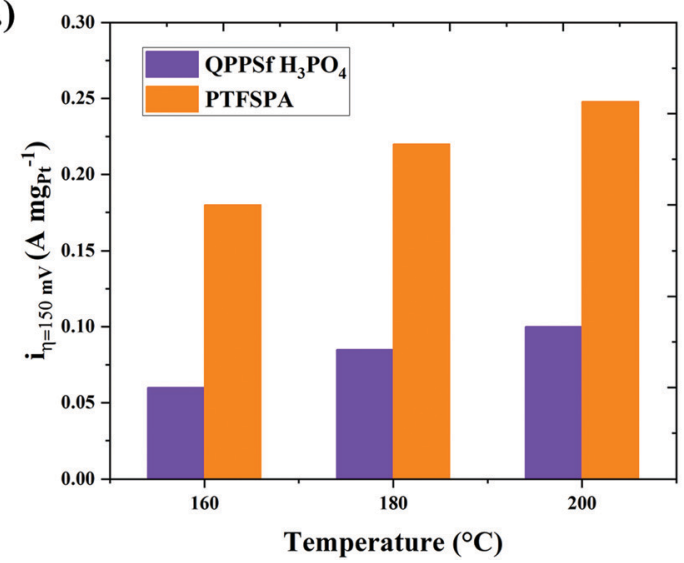

Fig. 2 (a) IDE platform with high density platinum nanowires ( $22 \mathrm{~nm}$ diameter and $28 \mathrm{~nm}$ in thickness). This platform is placed in a sealed, temperature-controlled chamber for HOR/HER measurements. (b) iR-corrected polarization curves for HOR/HER on IDE platform with PTFSPA and QPPSf $\mathrm{H}_{3} \mathrm{PO}_{4}$ thin films as a function of temperature $\left(160^{\circ} \mathrm{C}\right.$ to $\left.200^{\circ} \mathrm{C}\right)$. (c) The hydrogen permeability values $\left(P_{\mathrm{H}_{2}}\right)$ extracted from the limiting current values in the polarization curves (d) current density at $150 \mathrm{mV}$ (i.e., $i_{\mathrm{a} \eta=150 \mathrm{mv}}$ ) as a function of temperature for the two different thin film ionomers. 
the limiting current density values, as well as the film thickness values, temperature and concentration of hydrogen in the environmental chamber, we estimated the gas permeability values using eqn $(2)^{39}$ for the two different thin film hightemperature polymer electrolytes as a function of temperature (Fig. 2c). The hydrogen gas permeability values were $6 \times$ greater or more for the PTFSPA ionomer compared to the QPPSf $\mathrm{H}_{3} \mathrm{PO}_{4}$ thin film polymer electrolyte.

$$
\begin{gathered}
P_{\mathrm{H}_{2}}=D_{\mathrm{H}_{2}} H_{\mathrm{H}_{2}} \\
i_{\mathrm{lim}}=n \mathrm{FP}_{\mathrm{H}_{2}} \frac{C_{\mathrm{H}_{2}}}{\delta}
\end{gathered}
$$

$P_{\mathrm{H}_{2}}$ : permeability coefficient of hydrogen in the thin film ionomer $\left(\mathrm{cm}^{2} \mathrm{~s}^{-1}\right) . H_{\mathrm{H}_{2}}$ : solubility coefficient for hydrogen in the thin film ionomer (dimensionless). $D_{\mathrm{H}_{2}}$ : diffusion coefficient of hydrogen in the thin film ionomer $\left(\mathrm{cm}^{2} \mathrm{~s}^{-1}\right) . C_{\mathrm{H}_{2}}$ : concentration of hydrogen in the environmental chamber $\left(\mathrm{mol} \mathrm{cm}{ }^{-3}\right)$. $\delta$ : thin film ionomer thickness (cm). $n$ : number of electrons transferred for the reaction per equivalent of hydrogen. $F$ : Faraday's constant $\left(\mathrm{C} \mathrm{mol}^{-1}\right) . i_{\text {lim }}$ : limiting current density $\left(\mathrm{A} \mathrm{cm}^{-2}\right)$.
Next, the linear regime of the iR-corrected polarization curves was analyzed in order to assess how the different thin film ionomers affect HOR/HER kinetics. The iR-corrected potential values in the linear regime, which also corresponds to low current density values, is under mixed-control (i.e., reaction kinetics and mass transfer resistances dictate the current response). Here, we assume that the mass transfer resistance is not severe but not negligible because of the presence of the thin film ionomer coating. Fig. $2 d$ shows the current density at $150 \mathrm{mV}$ (i.e., $i_{@ \eta=150 \mathrm{mv}}$ ) for two different hightemperature thin film ionomers as a function of temperature. At $160{ }^{\circ} \mathrm{C}$, the $i_{@ \eta=150 \mathrm{mv}}$ value for the PTFSPA film was $4 \times$ greater for $\mathrm{HOR} / \mathrm{HER}$ when compared to QPPSf $\mathrm{H}_{3} \mathrm{PO}_{4}$. Increasing the temperature to $200{ }^{\circ} \mathrm{C}$ resulted in a larger enhancement for $i_{@ \eta=150 \mathrm{mv}}$ for PTFSPA, while the improvement for QPPSf $\mathrm{H}_{3} \mathrm{PO}_{4}$ was marginal.

In the next set of studies, membrane electrode assemblies (MEAs) were fabricated for single-cell ECHP studies. The MEAs consisted of QPPSf PBI $\mathrm{H}_{3} \mathrm{PO}_{4}$ HT-PEM separators and Pt/C gas diffusion electrodes (GDEs) that used QPPSf $\mathrm{H}_{3} \mathrm{PO}$ (termed MEA 1) and PTFSPA (termed MEA 2) as electrode binders. The iR-corrected single-cell ECHP polarization curves for the
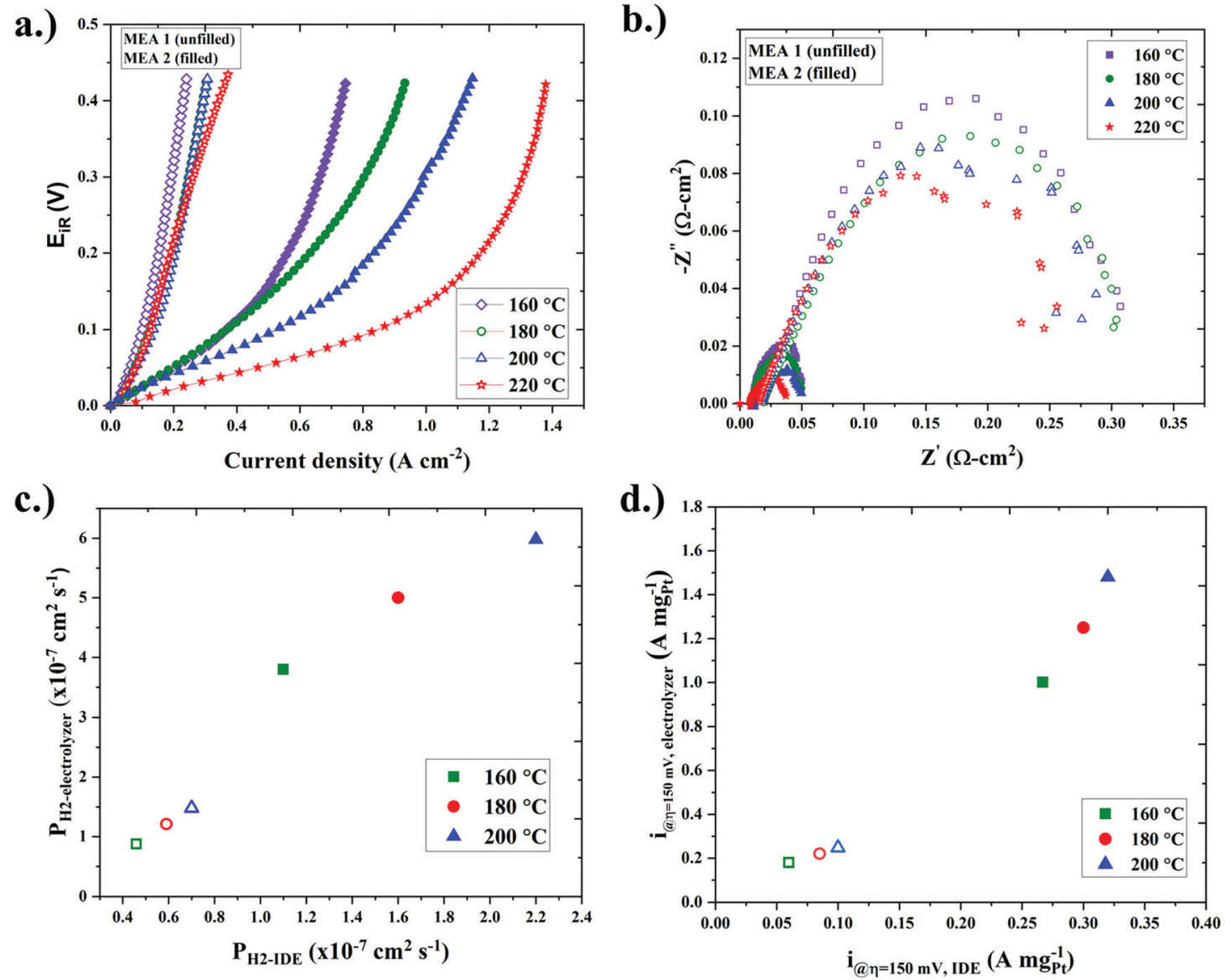

Fig. 3 (a) Single-cell ECHP iR-corrected polarization behavior with the same HT-PEM and Pt/C loadings $\left(0.5 \mathrm{mg}_{\mathrm{Pt}} \mathrm{cm}^{-2}\right)$ but with different types of electrode binders. (b) Nyquist plots from ECHP experiments with the MEAs featuring different electrode binders as a function of temperature. Correlation between the (c) permeability values $\left(P_{\mathrm{H}_{2}}\right.$, normalized to platinum loadings) and (d) current density at $150 \mathrm{mV}$ (i.e., $\left.i_{\mathrm{a} \eta=150 \mathrm{mv}}\right)$ in single-cell MEA ECHPs and IDEs. 
MEAs that feature the different electrode binders at different temperatures (160 to $220{ }^{\circ} \mathrm{C}$ ) are presented in Fig. 3a, and the non-iR corrected polarization curves are provided in Fig. S8 $(\mathrm{ESI} \dagger)$. There are two salient features in Fig. 3a: (i) the MEA with a PTFSPA electrode binder outperformed the MEA with a QPPSf $\mathrm{H}_{3} \mathrm{PO}_{4}$ electrode binder and (ii) as the cell temperature increased, the polarization decreased more with PTFSPA as the electrode binder, while the polarization remained about the same with QPPSf $\mathrm{H}_{3} \mathrm{PO}_{4}$ as the electrode binder.

The Nyquist plots from electrochemical impedance spectra taken at no applied potential during ECHP experiments are given in Fig. 3b. The charge-transfer resistance was $0.04 \Omega \mathrm{cm}^{2}$ or less with PTFSPA as the electrode binder, while the chargetransfer resistance for QPPSf $\mathrm{H}_{3} \mathrm{PO}_{4}$ was $>0.25 \Omega \mathrm{cm}^{2}$ (i.e., at least $6 \times$ greater). In the next set of analyses, the linear-regime and limiting current density values of the polarization curves were analyzed for extracting $i_{@ \eta=150 \mathrm{mv}}$ and $P_{\mathrm{H}_{2}}$ values for singlecell ECHPs. The $P_{\mathrm{H}_{2}}$ and $i_{@ \eta=150 \mathrm{mv}}$ values as a function of temperature are plotted in Fig. S9a and b (ESI $\dagger$ ). Similar to the observations from IDE studies, the $P_{\mathrm{H}_{2}}$ and $i_{@ \eta=150 \mathrm{mv}}$ values were greater for the MEAs containing PTFSPA as the binder over QPPSf $\mathrm{H}_{3} \mathrm{PO}_{4}$ as the electrode binder (e.g., $6 \times$ for $P_{\mathrm{H}_{2}}$ and $4-6 \times$

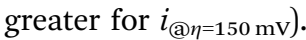

The lower charge-transfer resistance from Fig. $3 \mathrm{~b}$ and greater $i_{@ \eta=150 \mathrm{mV}}$ observed from Fig. S9b (ESI $\dagger$ ) for PTFSPA electrode binder might be due to lower phosphate anion adsorption on the platinum electrocatalyst. Phosphate and phosphonate anions hinder electrocatalyst utilization in both anode and cathode. ${ }^{42}$ Because QPPSf- $\mathrm{H}_{3} \mathrm{PO}_{4}$ has more phosphate groups per weight, more anion adsorption takes place accounting for the larger charge-transfer resistance and low $i_{@ \eta=150 \mathrm{mV}}$ when compared to PTFSPA. The binder PTFSPA has fewer phosphonate anions, and these anions are tethered to the backbone and its degrees of freedom with respect to translational motion is restricted when compared to $\mathrm{H}_{3} \mathrm{PO}_{4}$. Hence, these reasons account for the better current response observed for a given voltage in IDEs and single-cell MEA ECHP when using PTFSPA as the thin film electrolyte and electrode binder.

The correlations between $P_{\mathrm{H} 2}$ and $i_{@ \eta=150 \mathrm{mv}}$ attained from IDE and single-cell MEA ECHP studies are conveyed in Fig. 3c and d. A linear commensurate relationship was observed for the $P_{\mathrm{H} 2}$, and $i_{@ \eta=150 \mathrm{mV}}$ values between the different two platforms, indicating that the IDEs are useful for probing how potential new ionomer binders may affect ECHP electrode performance. The IDEs use $>100 \times$ less platinum than an MEA and far less ionomer material. Several IDE platforms can be loaded into a single environmental chamber and studied using multi-channel potentiostat, making it an excellent high-throughput tool for studying the electrochemical properties of thin film ionomers used as electrode binders.

Our initial studies using PTFSPA electrode binders were carried out with $1 \mathrm{mg}_{\mathrm{Pt}} \mathrm{cm}^{-2}$ in the MEA (Fig. 3a). To compare against the current state-of-the-art existing data on HT-PEM ECHPs in the literature, another MEA was fabricated with $2 \mathrm{mg}_{\mathrm{Pt}} \mathrm{cm}^{-2}$ in the MEA (equal loading on each electrode) with PTFSPA binder. The ECHP polarization curve of this MEA is given in Fig. $4 \mathrm{a}$ and the performance is compared against stateof-the art data in Fig. 4b. ${ }^{6,30}$ The HT-PEM ECHP with PTFSPA electrode binder displayed a very low voltage requirement (see Table 1) and best performance compared to the current HT-PEM ECHPs. ${ }^{6,30}$

To optimize the HT-PEM ECHP, future work with these materials will examine overpotential differences between the HOR and HER, similar to the asymmetric MEA approach by Neyerlin, Gasteiger, and co-workers, ${ }^{43}$ in addition to identifying the right binder loading in the electrodes and phosphonic acid loading in PTFSPA. In the report by Neyerlin, Gasteiger, and co-workers, $^{43}$ they observed almost identical overpotential terms for HOR and HER at a given current density for LTPEM ECHPs. However, HOR/HER overpotential values at low current density values may differ with the PTFSPA binder versus Nafion ${ }^{\circledR}$ (which is used for LT-PEM ECHP) because the PTFSPA

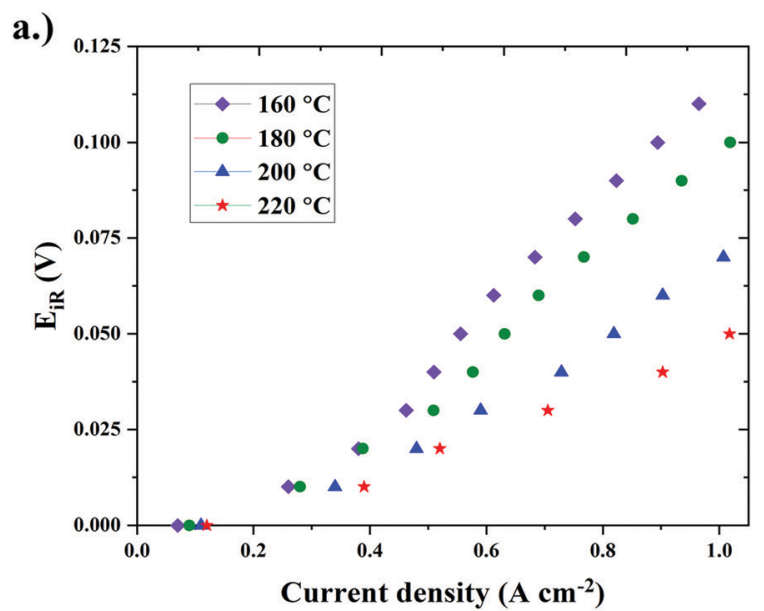

b.)

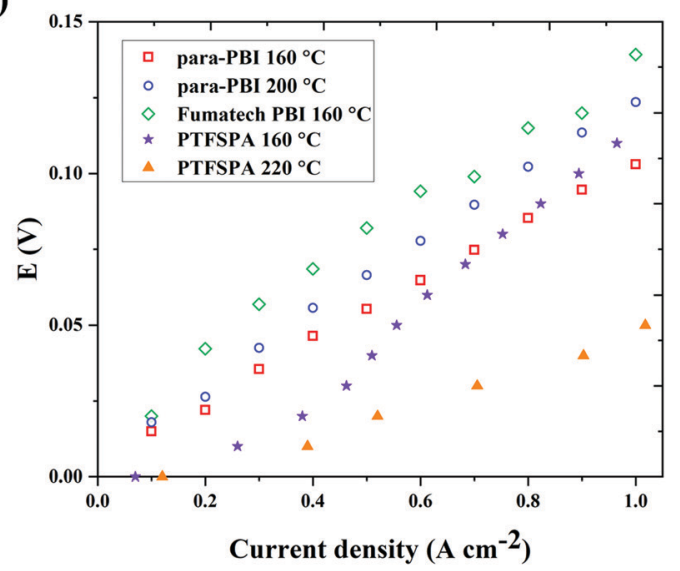

Fig. 4 (a) Single-cell ECHP iR-corrected polarization behavior using PTFSPA as the electrode binder and $1 \mathrm{mg}_{\mathrm{Pt}} \mathrm{cm}^{-2}$ for each electrode. The MEA used the QPPSf-PBI H $\mathrm{HOO}_{4} \mathrm{HT}$-PEM (b) the performance comparison against the current state-of-the art existing various single-cell HT-PEM ECHPs ${ }^{6,30}$ with PTFSPA electrode binder. 
Table 1 Performance comparison of various single-cell HT-PEM ECHPs with the same Pt loading in electrodes

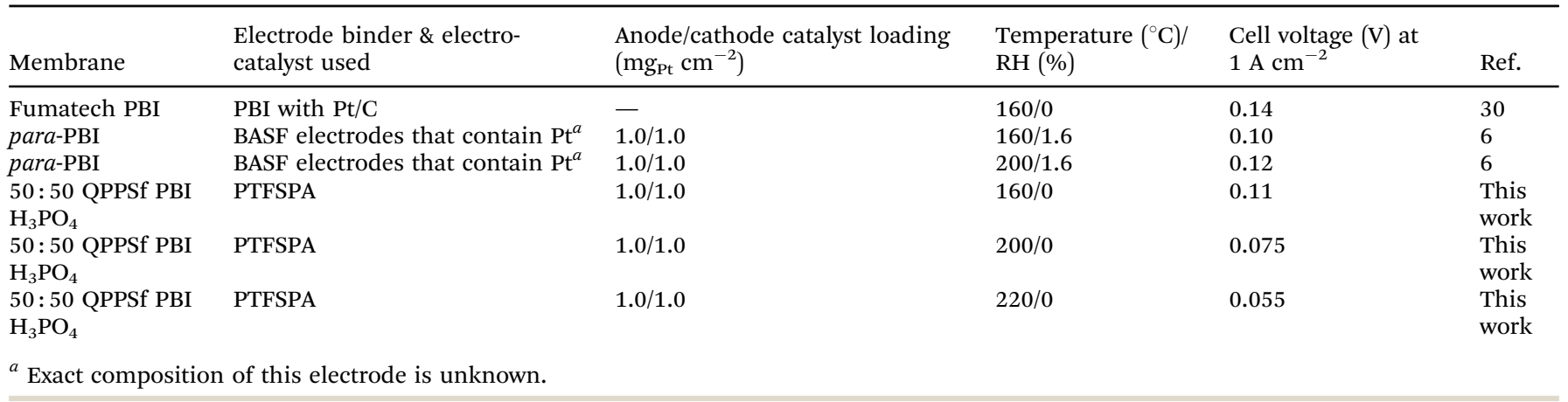

has lower acidity compared to Nafion ${ }^{\mathbb{R}}\left(\mathrm{p} K_{\mathrm{A}} \sim 1.5\right.$ versus $\mathrm{p} K_{\mathrm{A}}$ of 0 to -3 , respectively).

A notable difference between HT-PEM and LT-PEM ECHP studies in the literature is the platinum loading in the electrodes. LT-PEM ECHPs use about $0.5 \mathrm{mg}_{\mathrm{Pt}} \mathrm{cm}^{-2}$ to $0.8 \mathrm{mg}_{\mathrm{Pt}} \mathrm{cm}^{-2}$ in the MEA, while HT-PEMs typically use $2 \mathrm{mg}_{\mathrm{Pt}} \mathrm{cm}^{-2}$. Although LT-PEM ECHPs have better performance with lower platinum loading, high temperature operation of HT-PEM ECHPs assists in overcoming catalyst poisoning and deactivation due to contaminants in the hydrogen mixture (e.g., carbon monoxide (CO)). ${ }^{1,6,26,30}$ Hence, operating the ECHP at higher temperatures allows for more effective hydrogen separations and purification from mixtures with larger fractions of contaminants and smaller concentrations of hydrogen (i.e., a dirter mixture).

\section{Conclusions}

In summary, we show here that PTFSPA is a more effective electrode binder for ECHPs over QPPSf- $\mathrm{H}_{3} \mathrm{PO}_{4}$ binders because it does not contain liquid acid known to obfuscate hydrogen gas permeability and hinder reaction kinetics due to phosphate anion adsorption on the electrocatalyst surface. Using the IDE platform decorated with nanowire platinum catalysts for HOR/ HER studies, we unequivocally demonstrate that the measured thin film polymer electrolyte electrochemical properties correlate to single-cell ECHP polarization behavior. IDE platforms are useful for high-throughput assessments of potential new ionomer materials for use as electrode binders. Finally, implementing PTFSPA materials as electrode binders in HT-PEM ECHPs results in excellent performance of $1 \mathrm{~A} \mathrm{~cm}^{-2}$ at $55 \mathrm{mV}$.

\section{Author contributions}

G. V. synthesized and characterized materials, performed all experiments on IDEs and ECHPs. S. K. fabricated IDEs. D. B. fabricated IDE platforms with nanoscale PGM electrocatalysts and assisted with figures. C. G. Y. helped with ionic conductivity measurements. P. A. and G. S. synthesized random copolymers for block copolymer self-assembly. G. V. and C. G. A. wrote the manuscript and analyzed data. All authors reviewed and edited the manuscript.

\section{Conflicts of interest}

C. G. A. is a co-founder of a startup company, Ionomer Solutions LLC, that is in the process of licensing HT-PEM materials (US Patent Application \# 62/656,538) developed at Louisiana State University with plans for commercialization.

\section{Acknowledgements}

This material is based upon work supported by the U.S. Department of Energy's Office of Energy Efficiency and Renewable Energy (EERE) under the Advanced Manufacturing Office (AMO) Award Number DE-EE0009101. The views expressed herein do not necessarily represent the views of the U.S. Department of Energy or the United States Government. We thank Dr Rafel Cueto for assisting us with TGA measurements. We acknowledge the use of the LSU Shared Instrumentation, NMR, and Nanofabrication Facilities.

\section{References}

1 V. Atanasov, A. S. Lee, E. J. Park, S. Maurya, E. D. Baca, C. Fujimoto, M. Hibbs, I. Matanovic, J. Kerres and Y. S. Kim, Nat. Mater., 2021, 370-377.

2 W. E. Mustain, Curr. Opin. Electrochem., 2018, 12, 233-239. 3 Y. S. Kim, ACS Appl. Polym. Mater., 2021, 1250-1270.

4 A. Kobayashi, T. Fujii, C. Harada, E. Yasumoto, K. Takeda, K. Kakinuma and M. Uchida, ACS Appl. Energy Mater., 2021, 3, 2307-2317.

5 D. Li, E. J. Park, W. Zhu, Q. Shi, Y. Zhou, H. Tian, Y. Lin, A. Serov, B. Zulevi, E. D. Baca, C. Fujimoto, H. T. Chung and Y. S. Kim, Nat. Energy, 2020, 5, 378-385.

6 R. B. Kutz, Q. Chen, H. Yang, S. D. Sajjad, Z. Liu and I. R. Masel, Energy Technol., 2017, 5, 929-936.

7 V. M. Palakkal, L. Valentino, Q. Lei, S. Kole, Y. J. Lin and C. G. Arges, npj Clean Water, 2020, 3, 5.

8 A. P. Bhat, E. R. Reale, M. del Cerro, K. C. Smith and R. D. Cusick, Water Res., 2019, 3, 100027.

9 B. Choi, D. A. Langlois, N. Mack, C. M. Johnston and Y. S. Kim, J. Electrochem. Soc., 2014, 161, F1154-F1162.

10 A. Kongkanand and M. F. Mathias, J. Phys. Chem. Lett., 2016, 7, 1127-1137. 
11 A. Katzenberg, A. Chowdhury, M. Fang, A. Z. Weber, Y. Okamoto, A. Kusoglu and M. A. Modestino, J. Am. Chem. Soc., 2020, 142, 3742-3752.

12 K. More, R. Borup and K. Reeves, ECS Trans., 2019, 3, 717-733.

13 M. A. Modestino, D. K. Paul, S. Dishari, S. A. Petrina, F. I. Allen, M. A. Hickner, K. Karan, R. A. Segalman and A. Z. Weber, Macromolecules, 2013, 46, 867-873.

14 A. Kusoglu, D. Kushner, D. K. Paul, K. Karan, M. A. Hickner and A. Z. Weber, Adv. Funct. Mater., 2014, 24, 4763-4774.

15 D. K. Paul, R. McCreery and K. Karan, J. Electrochem. Soc., 2014, 161, F1395-F1402.

16 S. K. Dishari and M. A. Hickner, ACS Macro Lett., 2012, 1, 291-295.

17 S. K. Dishari and M. A. Hickner, Macromolecules, 2013, 46, 413-421.

18 S. K. Dishari, C. A. Rumble, M. Maroncelli, J. A. Dura and M. A. Hickner, J. Phys. Chem. C, 2018, 122, 3471-3481.

19 S. Farzin, A. Sarella, M. A. Yandrasits and S. K. Dishari, J. Phys. Chem. C, 2019, 123, 30871-30884.

20 A. Y. Abdulla, Undergraduate thesis, Princeton University, 2009.

21 I. Matanovic, S. Maurya, E. J. Park, J. Y. Jeon, C. Bae and Y. S. Kim, Chem. Mater., 2019, 31, 4195-4204.

22 R. Subbaraman, D. Strmcnik, V. Stamenkovic and N. M. Markovic, J. Phys. Chem. C, 2010, 114, 8414-8422.

23 S. Sambandam and V. Ramani, Phys. Chem. Chem. Phys., 2010, 12, 6140-6149.

24 S. Sambandam, J. Parrondo and V. Ramani, Phys. Chem. Chem. Phys., 2013, 15, 14994-15002.

25 A. Chaichi, G. Venugopalan, R. Devireddy, C. Arges and M. R. Gartia, ACS Appl. Energy Mater., 2020, 3, 5693-5704.

26 G. Venugopalan, K. Chang, J. Nijoka, S. Livingston, G. M. Geise and C. G. Arges, ACS Appl. Energy Mater., 2020, 3, 573-585.

27 K.-S. Lee, J. S. Spendelow, Y.-K. Choe, C. Fujimoto and Y. S. Kim, Nat. Energy, 2016, 1, 16120.
28 K.-S. Lee, S. Maurya, Y. S. Kim, C. R. Kreller, M. S. Wilson, D. Larsen, S. E. Elangovan and R. Mukundan, Energy Environ. Sci., 2018, 11, 979-987.

29 A. S. Lee, Y.-K. Choe, I. Matanovic and Y. S. Kim, J. Phys. Chem. A, 2019, 7, 9867-9876.

30 K. A. Perry, G. A. Eisman and B. C. Benicewicz, J. Power Sources, 2008, 177, 478-484.

31 K. Fishel, G. Qian, G. Eisman and B. C. Benicewicz, in High Temperature Polymer Electrolyte Membrane Fuel Cells, ed. Q. Li, Springer International Publishing, Switzerland, 2016, pp. 527-540.

32 F. Huang, A. T. Pingitore and B. C. Benicewicz, ACS Sustainable Chem. Eng., 2020, 8, 6234-6242.

33 F. Huang, A. T. Pingitore and B. C. Benicewicz, J. Electrochem. Soc., 2020, 167, 63504.

34 C. Jackson, L. F. J. M. Raymakers, M. J. J. Mulder and A. R. J. Kucernak, Appl. Catal., B, 2020, 268, 118734.

35 C. Jackson, L. F. J. M. Raymakers, M. J. J. Mulder and A. R. J. Kucernak, J. Power Sources, 2020, 472, 228476.

36 A. Y. Abdulla, Undergraduate thesis, Princeton University, 2009.

37 R. P. Singh, X. Li, K. W. Dudeck, B. C. Benicewicz and K. A. Berchtold, Polymer, 2017, 119, 134-141.

38 A. T. Pingitore, F. Huang, G. Qian and B. C. Benicewicz, ACS Appl. Energy Mater., 2019, 2, 1720-1726.

39 D. Chen, A. Kongkanand and J. Jorne, J. Electrochem. Soc., 2019, 166, F24-F33.

40 D. Bhattacharya, S. Kole, O. Kizilkaya, J. Strzalka, P. P. Angelopoulou, G. Sakellariou, D. Cao and C. G. Arges, Small, 2021, DOI: 10.1002/smll.202100437.

41 V. Atanasov, A. Oleynikov, J. Xia, S. Lyonnard and J. Kerres, J. Power Sources, 2017, 343, 364-372.

42 Y. Hu, Y. Jiang, J. O. Jensen, L. N. Cleemann and Q. Li, J. Power Sources, 2018, 375, 77-81.

43 K. C. Neyerlin, W. Gu, J. Jorne and H. A. Gasteiger, J. Electrochem. Soc., 2007, 154, B631-B635. 